\title{
28 Research Square \\ The Lived Experiences of Parents of Iranian Young Women with Multiple Sclerosis
}

\section{Marzieh Panahi}

Ardebil University of Medical Sciences

\section{Zahra Tazakori}

Ardebil University of Medical Sciences

Mansoureh Karimollahi ( $\nabla$ karimollahi@gmail.com )

Ardabil University of Medical Sciences https://orcid.org/0000-0002-4257-2088

\section{Research article}

Keywords: Experiences, Invisible MS, Parenting, MS, Phenomenology

Posted Date: December 17th, 2019

DOI: https://doi.org/10.21203/rs.2.19039/v1

License: (1) This work is licensed under a Creative Commons Attribution 4.0 International License. Read Full License 


\section{Abstract}

Background: Chronic illness in children causes more mental health risks for parents than other members of the family. Therefore, exploring the experiences of parents living with young women who have multiple sclerosis and presenting them to healthcare planners and managers can have a positive impact on community health. This study aimed to explore the experiences of parents of young women with multiple sclerosis in Iran.

Methods: This research was a phenomenological study, and sampling was continued until data saturation, and 12 participants were chosen. The data were gathered using semi-structured interviews and analyzed using Colaizzi's method.

Results: Open coding resulted in 450 codes, and after several stages of analysis and integration of similar codes, five main concepts, and 21 sub-concepts was produced. The main concepts included distress, trapping, adaptation barriers, response to illness, and reconciliation with the disease.

Conclusion: This study showed the disease affects all dimensions of the parents' life and can lead to the experiences that are new to them and may lead to confusion. These findings can lead to more effective parental care for their daughters. It can also reduce the burden of disease on the family, the health system, and the community.

\section{Background}

Multiple sclerosis (MS) is the most common neurological disease among young adults affecting more than 100,000 people in the United Kingdom in a ratio of 1:3 male to female [1]. More than two and a half million people worldwide are affected by multiple sclerosis [2]. In the United States, about 400,000 people are affected by the disease [3]; and 60,000 people are currently affected in Iran. Also, the prevalence of MS in Tehran has increased from 51.9/100,000 in 2008 to 74.28/100,000 in 2011[4]. Besides, the prevalence of multiple sclerosis in Iran is twenty times higher than in other countries in the region [2]. Maghzi et al. (2010) found a significant increase in the incidence of MS among females for the last decades in the Isfahan province of Iran [5], most of them are young women at the peak of social responsibility [6]. Women, in addition to their personal and family responsibilities, are determinative and critical in social activities, and establishing a healthy community depends on their active presence in society [7]. Multiple sclerosis affects the life quality of patients and their families by inflicting family life, economic conditions, and social communication $[8,9]$.

The burden of the disease in the caregiver pretends to be both primary and secondary ways: the principal grounds in the demands of physical care and the psychological stresses caused by the stigma, and the secondary form are origins by taking the role of the caregiver [9].

Family emotions can positively or negatively affect the patient's recovery and his/her response to the illness [10]. Also, parents adopt new roles and responsibilities to preserve the family's routine and other 
life commitments [11]; In the literature, the need for psychological support of the caregiver is highlighted, and it is stated that the lack of social support is related to mental distress $[12,13]$.

Cheung and Hocking have argued that the experience of the caregiver who is concerned with his/her health, the relationship with their wife, and the lack of support can lead to the internalization of mental stress [14]. Chronic illness in children also creates more mental health risks for parents than other members of the family [11]. Therefore, exploring the experiences of parents living with young women who have multiple sclerosis and presenting them to health care managers can have a positive impact on the health of the community. However, studies conducted in Iran about MS have focused on the epidemiology of illness and perceptions of carers and their quality of life, which have been done quantitatively [9, 15-22]. So, this study aimed to explain the experiences of parents who have daughters with multiple sclerosis. To the best of our knowledge, according to the literature, this is the first research in the world, on the experiences of parents of young women with multiple sclerosis.

\section{Methods}

2.1. Design: Considering the purpose of this study that is exploring the experiences as lived, this study was conducted using a descriptive phenomenological approach. The researchers started this study after receiving the code of ethics from the Ardabil University of Medical Sciences.

2.2. Data Collection: The statistical population consisted of the parents of young women who were members of the MS Association of Ardabil, Iran, and the data were collected from February 19 to December 5, 2018. The participants were chosen using a purposeful sampling method based on their knowledge of the phenomenon and the desire to express their information. Data was saturated in a sample size of 12 people. The parents who have a daughter with multiple sclerosis, have the willingness to participate in the study and signed the informed consent form, and their daughter had no other chronic illness other than MS were eligible to participate.

The data were gathered using semi-structured, in-depth interviews, and the researchers tried to extract the experiences of the parents in their language without any interference. After getting the verbal and written consent of the participants, a digital voice recorder was used to record the interviews. Throughout the interview, the researcher tried to "bracketing" by putting aside all feelings and thoughts about the subject of the study. The interview was conducted in a quiet place where had the most convenience for the interviewees. Some interviews were held at the MS Society, some at the workplace of the parents, some at the interviewees' home or in the park, and the time was adjusted according to the interviewees' will.

The interview was begun with general questions like:

What experiences do you have with your daughter, who has MS? What is the effect of your daughter's illness on your life? Talk about what has happened to you after your daughter started suffering this disease. And in cases, the participant experienced difficulties in describing his/her experience, the researcher put forward follow-up questions for clarity. Based on participants 'responses and the results of 
the analysis of previous interviews, questions might be changed so that the researcher could get a better understanding of the participants' statements.

The duration of the interviews was between $45-120$ minutes. The interview continued as long as the participant fully described his/her experience and no longer needed clarification.

2.3. Analysis: The analysis was performed simultaneously with data collection. Since the aim of the study was a comprehensive descriptive study of the parents' lived experiences, Colaizzi's method was used for data analysis, which was done in seven steps. The first step was to collect participants' descriptions of the phenomenon. This was done recording participants' voices by digital voice recorder during the interview. In the second step, all interviews were written verbatim, and then with reading several times, we tried to extract the meaning of the statements. In the third stage, after reading all transcripts, the meaningful information and comments associated with the studied subject were underlined, and the essential sentences were recognized. In the fourth stage, the researcher tried to extract a concept that expressed the meaning of the interviewee from each expression. In the fifth step, the concepts were carefully read and were categorized based on the similarity; and was put together for a full description of the phenomenon under study, and general categories were created. In the sixth stage, we provided a comprehensive description of the phenomenon under investigation, which is as clear as possible and without any ambiguity, and the final step was the accreditation of the findings. An example of the analysis process is presented in Table 1.

Allowing sufficient time for data collection (about 17 months), establishing adequate and appropriate rapport with participants, using participants' comments to confirm extracted codes and categories (eight participants), reviewing interviews, codes, and categories by consulting and advising faculty member (all interviews), maximum diversity of samples in gender, age, disease history, and education were taken for consistency.

\section{Results}

Demographic characteristics of the participants in the study are presented in table 2. Open coding let to extracting 450 codes, which were classified in 22 sub-concepts, and finally, five concepts "distress, strangulation, barriers to coping and reconciliation with the disease" were resulted (Table 3 ).

\subsection{Distress}

Confusion and not having of any picture of future condition and responsibilities and the constant concern of what will happen in the future cause mental distress in the parents, which was resulted from the combination of the four sub-concepts of concern and fear, disappointment and dissatisfaction, a roaring future and mental engagement.

"I'm worried, for example, I say what will happen to my daughter after my death?" (A 60-year-old Mother) 
The inconveniences and frustrations that are caused in parents are sometimes due to the unpredictable nature of the disease, and sometimes because of their child's attitude to the illness, lack of understanding of their condition by others, and the issues which have been imposed on them during their child's illness.

"Now, its ten days that our relatives know my daughter's illness; they keep ringing and ask how she is. I say she's fine. They knew after two and a half years, but if they knew before that, they would ring every day, I'm upset with their behavior". (A 48-year-old mother)

The recurrent nature of the disease, the unexpectedness of the time of attacks, and the lack of definite treatment causes instability in the lives of patients and families and leads in the experience of a roaring future. In this research, parents said they are concerned about their daughter's career, marriage, and schooling in the future.

"Asks like this, with whom will I marry? When will I be married? Oh my God, what can I say to her?" (A 38year-old mother)

\subsection{Crippled}

Parents stated because of the new responsibilities imposed on them, and they could no longer be present in the community leading to a sense of being confined in the parents. This concept was obtained from two sub-concepts of burnout and being desperate.

Occasionally, attempted efforts or obstacles lead to some sense of incapability, disability, and desperate.

"I did everything. I took her to the best doctors in Tehran, I took her to an herbal doctor, I took her to the bee therapy, and I do not know what I'm going to do now? We can't do anything?" (A 53-year-old father)

One of the effects of illness on parents is physical or mental burnout. "When they told my daughter is ill, I became ill too, I could not raise my head, doctors said it's because your daughter got sick!" (A 60 -year- old mother)

\subsection{Adaptation barriers}

During the process of rehabilitation of the disease, issues hinder the route. According to the participants' statements, these barriers consisted of sub-concepts of "ups and downs of diagnosis", "economic burden" and "problems with the treatment process".

Uncertainty of diagnostic tests, lack of access to skilled physicians, and diagnostic facilities, an incorrect diagnosis can be cases that add to the challenge of the disease, which we named it "ups and downs" of diagnosis in our study.

"She had nausea and vomiting, her legs were paralyzed, I was not at home, and her dad had no idea, we went to the doctor, they did not say what it was. Later she was hospitalized; CT and MRI machines were 
broken, they sent us to Tabriz, where they diagnosed, hospitalized, and injected cortisones to my daughter". (A 38 -year- old mother)

One of the issues that people often face after the illness is financial and economic problems, including the cost of diagnosis, treatment such as drugs and supplements, hospitalization, and food. These problems were more pronounced in parents with lower economic classes. "I cannot completely take care of my daughter, but I'm trying to reduce the cost of nutrition or recreation of myself or my husband, but do not for my daughter". (A 42-year-old mother)

\subsection{Reactions to the disease}

Parents perceive each stage of the disease differs from the previous period, and according to their understanding, their response to the illness is different. We named it "reaction to the disease," and it was obtained combining the following sub-concepts of denial, bargaining, concealment of the disease, resort, and prayer, and interpretations of the disease.

"Because this disease was unexpected to me, I did not believe it, and I did not accept it, I could not believe it, of course, still after years now, I did not accept that my daughter has this problem". (A 42 -year-old mother)

"We took our daughter to Tabriz, we said that maybe MRI has a problem, maybe they are lying to us, and maybe they are mistaken". (A 60-year-old mother)

"Except my children, nobody knows my daughter's illness; we know it (MS) bad, thanks to God, now she's good, like ordinary people". (A 61-year-old Mother)

"Since my daughter has this illness, I go to the mosque, I read the Qur'an, I seek the help of God, I pray; I say, my God, my daughter, has a little child, please have mercy on her!" (A 58-year-old mother)

\subsection{Compromise with the disease}

After a while, parents accept their daughters' illness. Parents learn how to manage and treat their daughters and others. They also change their lifestyle for their daughter's comfort and better coping with the disease. This concept is consisted of accepting, hypothesizing of the cause of the illness, satisfaction, family mobilization, managing others, changing lifestyles, and learn the tricks.

"At first, we said the diagnosis might be not correct, we did not believe it, but then we saw the symptoms, and we believed it ..." (A 61-year-old mother)

"I asked myself what kind of disease this is. Why this happened to us?" Maybe it happened because our financial situation was not good. Perhaps this happened because we did not eat good food... This disease is like a cold, does it have a virus? I have MS. Did my daughter have a higher chance of having MS?" (A 38-year-old Mother) 
Parents accept the condition that they could not imagine being able to survive in that condition before their daughters' illness.

"The reaction of my daughters' friends was perfect; none of them made my daughter upset!" (A 48-yearold mother)

"My daughter's illness afflicted me in my life, for example, I could not have a child again, I had stress, I said," I have to raise her, it is costly! "(A 53-year-old father)

The onset of chronic illness in a family where the members of the family, especially parents, who struggle for a long time with the disease makes them familiar with the diet, medication, care, and how to deal with their sick daughter.

"It was very hard at the beginning, we did not know where we can get her medicine, or how to get it, we didn't know the Red Crescent helps for the drugs, we bought it from the ordinary pharmacy, now it's better, we know a lot of things" (A 60-year-old mother)

\section{Discussion}

At the beginning of the diagnosis, parents have apprehension and fears that lead to mental preoccupation; also, the unpredictability of the future is added and leads to the distress in them. Their concerns are about the progress of the disease, treatment process, fear of the illness disclosure and their daughter's future life which would be minimized by the emotional and spiritual support. In a study on the psychological and social factors leading to the stress in patients with multiple sclerosis, Mohammadi Rezve (2009) declared that the most stressors were concern about providing medical expenditures, marriage, and the future [23].

Distress and its improper management result in the parents being destitute and exhausted, which makes them more confined. Tolerating the various effects of their daughter's chronic disease by parents causes physical and mental changes in them, which exacerbate them in the long-term and endanger their social and even physical activities. Ali et al. (2012) stated that the stress that parents described as the presence of problems, difficulties, or complications of the disease were caused by illness and affected their life, and lack of support leads to individual isolation and loneliness [24].

Parents always strive to accept and adapt to the situation created, but they face obstacles on this path. Obstacles that parents faced in our research are the ups and downs of diagnosis, economic burden, and the problems of the treatment process.

Jadid-Mylani et al. (2012) stated most of the parents had been referred to the physician for symptoms such as anorexia, weight loss, and pallor, but underestimation and incomplete testing caused the disease not to be diagnosed at the beginning, the disease progressed, and the opportunity for treatment was lost [25]. 
Mendenhall \& Mount (2011) also found that chronic illness involves high and prolonged costs, which can increase the stress of the disease in families and significantly affects their quality of life [26].

With the onset of symptoms, some parents deny their child's illness, some complain about the situation they faced, some parents prefer to conceal their daughter's disease, and some are disappointed with cure and only resort to God and pray.

Mendenhall \& Mount (2011) found that the psychological impact of the disease on the parents is high, which sometimes leads to denial [26]. Jadid-Mylani et al. (2012) also mentioned that parents did not like to disclose their child's illness and concealed their child's illness [25]. Balejani et al. (2011) stated that spirituality sometimes referred to as spiritual well-being, religion, and religious practices and had a significant effect on increasing the life expectancy and quality of life of patients with cancer and their families [27].

Each parent comprehends his/her daughter's disease in a unique form, and they live with their understanding of the disease; some consider their daughter's illness as commonplace, and some find it hard and untreatable. Parents depending on their background and their current condition, show shock, crying, and sleepless nights when they hear their daughter's disease. Jadid-Mylani et al. (2012) concluded that when parents understand their child's illness, they get entirely hopeless and frustrated, and, and they wish they would die instead of their child supposing cancer as an untreatable disease [25]. Ashum and Nidhi (2004) found that diagnosis of disabilities in children often leads to shock, and typically leads to changes in home and family life, and challenges the underlying assumptions of life. Therefore, at this stage, changes may occur, the person's life collapses, changes, or fails to continue, and there is a need for more support for new ways in life [28].

After the early stages of diagnosing and confronting the disease, the parents accept their daughter's illness and seek the causes of illness; they accept the current conditions and use their full ability to improve conditions in that all members of the family help them. They learn how to handle the people around their daughters and change their lifestyles for their daughter's convenience and gradually learn the tricks or how to deal with the disease; in other words, compromise with the disease. In fact, in this stage, the parents can help their daughter cope with new conditions.

So, parents are forced to change their way of life to experience a better life. This change in lifestyle, which is a positive indicator, does not mean that parents are unable to recognize problems or do not see the issues and deny it but indicates that parents want to make sense of the success of life in new situations and continue it throughout their lives. They experience a good life every day, despite their sadness, and by accepting the disease, they choose suitable adaptation strategies and thus can find meaning in their lives, emphasizing positive outcomes [28].

Strickland et al. (2015) mentioned that participants described the support of patients with MS as a "shared journey", in which a shared experience is created between the person with MS and people who have emotional problems, sharing some of their fretfulness, fears, and distress [29]. 


\section{Conclusion}

Multiple sclerosis is a chronic and costly illness that challenges the continuous and orderly process of life. The experiences of the parents of daughters with multiple sclerosis show that each parent understands his/ her daughter's disease in a unique form, and they live with their understanding of the disease, some consider their daughter's illness as commonplace and some find it hard and untreatable. These understandings can lead to the experiences that are new to them, which may lead to confusion. Parents are forced to change their way of life to experience a better life, so they learn how to manage and treat their daughters and others.

Therefore, exploring the experiences of parents of daughters suffering multiple sclerosis, due to the extent of the role they play in the family as the most essential carers, can help the health care planners and managers to address their problems and lead to more effective care for them and also can reduce the burden of disease on the family, the health system, and the community.

\section{Declarations}

Ethics approval and consent to participate: The authorization to conduct research was obtained from the Ethics Committee of Ardabil University of Medical Sciences (IR.ARUMS.REC.1395.114).

-Consent for publication: all authors agreed signed consent for publication form -Availability of data and material: The authors are not allowed to share the analysis datasets of the current study due to data protection regulations.

-Competing interests: The authors have no discrepancies in their interests.

-Funding: This article has driven of a MSc thesis funded by Ardabil University of Medical Sciences, Ardabil, Iran.

-Authors' contributions: Study design: Mansoureh Karimollahi, Zahra Tazakori, Marzieh Panahi; Collection and analysis: Mansoureh Karimollahi, Zahra Tazakori, Marzieh Panahi; Article Writing: Mansoureh Karimollahi, Zahra Tazakori, and Marzieh Panahi

-Acknowledgments: The authors thank all young women with MS and their families who participated in interviews without whom this work would not be feasible

\section{References}

[1] McClurg D, Bugge C, Elders A, Irshad T, Hagen S, Moore KN, et al. Factors affecting continuation of clean intermittent catheterization in people with multiple sclerosis: Results of the COSMOS mixedmethods study. Mult Scler J 2019;25:727-39. doi:10.1177/1352458518768722. 
[2] Gafari S, Khoshknab MF, Nourozi K, Mohamadi E. Informal Caregivers' Experiences of Caring of Multiple Sclerosis Patients: A Qualitative Study. Iran J Nurs Midwifery Res 2017;22:243-7. doi:10.4103/1735-9066.208168.

[3] Dilokthornsakul P, Valuck RJ, Nair K V., Corboy JR, Allen RR, Campbell JD. Multiple sclerosis prevalence in the United States commercially insured population. Neurology, 2016;86:1014-21.

doi:10.1212/WNL.0000000000002469.

[4] Heydarpour P, Mohammad K, Yekaninejad MS, Elhami SR, Khoshkish S, Sahraian MA. Multiple sclerosis in Tehran, Iran: A joinpoint trend analysis. Mult Scler J 2014;20:512. doi:10.1177/1352458513494496.

[5] Maghzi AH, Ghazavi H, Ahsan M, Etemadifar M, Mousavi SA, Khorvash F, et al. Increasing female preponderance of multiple sclerosis in Isfahan, Iran: A population-based study. Mult Scler 2010;16:35961. doi:10.1177/1352458509358092.

[6] Qaderi K, Merghati Khoei E. Female sexuale problems in multiple sclerosis and its association with quality of life. J Urmia Nurs Midwifery Fac 2013;11.

[7] Alizadeh M. The role of women in development. Women Cult 2010;5:49-59. doi:10.1057/palgrave.development.1100348.

[8] Malcomson K.S., Dunwoody L., Lowe-Strong A.S. Psychosocial interventions in people with multiple sclerosis: A review. J Neurol 2007:1-13. doi:http://dx.doi.org/10.1007/s00415-006-0349-y.

[9] Masoodi R, Alhani F, Rabiei L, Majdinasab N, Moghaddasi J, Esmaeili SA, et al. The effect of familycentered empowerment model on quality of life and self-efficacy of multiple sclerosis patients family care givers. Iran J Nurs Res 2013;7:32-43.

[10] Nolte E, McKee M. Caring for people with chronic conditions: a health system perspective. 2008. DOI:ISBN 9789289042949.

[11] Jones V, Whitehead L, Crowe MT. Self-efficacy in managing chronic respiratory disease: parents' experiences. Contemp Nurse 2016;52:341-51. doi:10.1080/10376178.2016.1213647.

[12] Pakenham KI. The nature of caregiving in multiple sclerosis: development of the caregiving tasks in multiple sclerosis scale. Mult Scler 2007;13:929-38. doi:10.1177/1352458507076973.

[13] O'Connor EJ, McCabe MP, Firth L. The impact of neurological illness on marital relationships. J Sex Marital Ther 2008;34:115-32. doi:10.1080/00926230701636189.

[14] Cheung J, Hocking P. Caring as worrying: The experience of spousal carers. J Adv Nurs 2004;47:47582. doi:10.1111/j.1365-2648.2004.03126.x. 
[15] Masoudi R, Soleimany MA, Moghadasi J, Qorbani M, Mehralian H, Bahrami N. Effect of progressive muscle relaxation program on self-efficacy and quality of life in caregivers of patients with multiple sclerosis. J Ghazvin Univ Med Scie 2011;15:41-7.

[16] Etemadifar M, Maghzi AH. Sharp increase in the incidence and prevalence of multiple sclerosis in Isfahan, Iran. Mult Scler J 2011;17:1022-7. doi:10.1177/1352458511401460.

[17] Elhami SR, Mohammad K, Sahraian MA, Eftekhar H. A 20-year incidence trend (1989-2008) and point prevalence (March 20,2009) of multiple sclerosis in Tehran, Iran: A population-based study. Neuroepidemiology, 2011;36:141-7. doi:10.1159/000324708.

[18] Etemadifar M, Sajjadi S, Nasr Z, Firoozeei TS, Abtahi SH, Akbari M, et al. Epidemiology of multiple sclerosis in Iran: A systematic review. Eur Neurol 2013;70:356-63. doi:10.1159/000355140.

[19] Alonso A, Cook SD, Maghzi AH, Divani AA. A case-control study of risk factors for multiple sclerosis in Iran. Mult Scler J 2011;17:550-5. doi:10.1177/1352458510397685.

[20] Maghzi AH, Etemadifar M, Shaygannejad V, Saadatnia M, Salehi M, Hassanzadeh A. Conjugal multiple sclerosis in Isfahan, Iran: A population-based study. Mult Scler 2007;13:673-5. doi:10.1177/1352458506072092.

[21] Ghojazadeh M, Taghizadeh M, Abdi S, Azami-Aghdash S, Andalib S, Farhoudi M. Fear of Disease Progression in Patients with Multiple Sclerosis: Associations of Anxiety, Depression, Quality of Life, Social Support and Knowledge. J Clin Res Governance 2016;3:141-6. doi:10.13183/jcrg.v3i2.105.

[22] Ghandehari K, Riasi HR, Nourian A, Boroumand AR. Prevalence of multiple sclerosis in northeast of Iran. Mult Scler 2010;16:1525-6. doi:10.1177/1352458510372150.

[23] Mohammadi Rezve N, Afshar H. Determining psychological and social factors of stress in multiple sclerosis patients. J Fundam Ment Heal 2009;10:305-10.

[24] Ali S, Sabih F, Jehan S, Anwar M JS. Psychological distress and coping strategies among parents of beta-thalassemia major patients. Int. Conf. Clean Green Energy, 2012.

[25] Jadid mylani M, Ashk torab T, Abbed saidi J, Alavi Majd H. The Effect of Peer Groups on Promoting the Physical Health Status of Patients with Multiple Sclerosis: The Reid Self-Extreme Theory Test. Heal Promot Manag 2012;1:34-44.

[26] Mendenhall A, Mount K. Parents of Children with Mental Illness: Exploring the Caregiver Experience and Caregiver-Focused Interventions. Fam Soc J Contemp Soc Serv 2011;92:183-90. doi:10.1606/10443894.4097.

[27] Balejani E, Kheshabi J, Amanpour E AN. A Study of the Relationship Between Spiritual Health, Religion, and Hope in Cancer Patients. Hayat, J Sch Nurs Midwifery, Tehran Univ Med Sci 2011;17:27-37. 
[28] Ashum G, Nidhi S. Positive perceptions in parents of children with disabilities. Asia Pacific Disabil Rehabil J 2004;15(1):22-7.

[29] Strickland K, Worth A, Kennedy C. The experiences of support persons of people newly diagnosed with multiple sclerosis: An interpretative phenomenological study. J Adv Nurs 2015;71:2811-21. doi:10.1111/jan.12758.

\section{Tables}

Table 1: Demographic profile of the participants

\begin{tabular}{|l|c|c|c|c|}
\hline Role & $\begin{array}{c}\text { age } \\
\text { (years) }\end{array}$ & $\begin{array}{l}\text { Duration of the disease } \\
\text { (months) }\end{array}$ & Education & Occupation \\
\hline Mother & 42 & 48 & High school & Housewife \\
\hline Mother & 48 & 30 & Elementary & Housewife \\
\hline Mother & 60 & 120 & $\begin{array}{c}\text { Associate } \\
\text { degree }\end{array}$ & $\begin{array}{c}\text { Retired } \\
\text { teacher }\end{array}$ \\
\hline Father & 53 & 168 & Middle school & Driver \\
\hline Mother & 38 & 7 & Middle school & Housewife \\
\hline Mother & 60 & 72 & Illiterate & Housewife \\
\hline Mother & 63 & 48 & Illiterate & Housewife \\
\hline Father & 68 & 96 & High school & plumber \\
\hline Father & 78 & 120 & Elementary & Vendor \\
\hline Mother & 61 & 144 & Elementary & Housewife \\
\hline Mother & 58 & 108 & Elementary & Housewife \\
\hline Mother & 48 & 84 & Elementary & Housewife \\
\hline
\end{tabular}

Table 2: analysis process 


\begin{tabular}{|c|c|c|}
\hline Quotes & codes & Sub themes \\
\hline $\begin{array}{l}\text { I think with myself, God, will my daughter } \\
\text { cured or not? }\end{array}$ & $\begin{array}{l}\text { The unpredictability of } \\
\text { the daughter's disease } \\
\text { status in the future }\end{array}$ & $\begin{array}{l}\text { A roaring } \\
\text { future }\end{array}$ \\
\hline $\begin{array}{l}\text { After my daughter's illness, the stress caused a } \\
\text { hearing problem in me, and I got diabetes. }\end{array}$ & $\begin{array}{l}\text { Getting sick due to } \\
\text { daughter's illness }\end{array}$ & burnout \\
\hline $\begin{array}{l}\text { Always, I say, God, what is this disease?! Why } \\
\text { me? Look now, how many people are there?! } \\
\text { From all around, why only me?! }\end{array}$ & Why me? & Bargaining \\
\hline $\begin{array}{l}\text { I think that the problems of life, both economic } \\
\text { and financial, have caused the disease to come } \\
\text { to light }\end{array}$ & $\begin{array}{l}\text { Hypothesis about the } \\
\text { daughter's illness }\end{array}$ & $\begin{array}{l}\text { Hypothesizing } \\
\text { the cause of } \\
\text { the illness }\end{array}$ \\
\hline We did not go where we could not get her! & $\begin{array}{lr}\text { Constraints } & \text { on } \\
\text { socialization due } & \text { to } \\
\text { daughter's illness } & \end{array}$ & $\begin{array}{l}\text { Change in } \\
\text { lifestyle }\end{array}$ \\
\hline
\end{tabular}

Table 3: themes and subthemes

\begin{tabular}{|l|l|}
\hline sub-themes & themes \\
\hline $\begin{array}{l}\text { Sorry and fear } \\
\text { roaring future }\end{array}$ & Distress \\
Mental preoccupation & \\
\hline Desperation & \\
Burnout & Crippled \\
\hline $\begin{array}{l}\text { Ups and downs of detection } \\
\text { Economic burden }\end{array}$ & \\
\hline $\begin{array}{l}\text { Denial of the treatment process } \\
\text { Bargain } \\
\text { Concealing the disease } \\
\text { Resort and prayer } \\
\text { Interpretation of disease }\end{array}$ & Adaptation barriers \\
\hline $\begin{array}{l}\text { Accepting } \\
\text { The hypothesizing the cause of the disease } \\
\text { Family mobilization } \\
\text { Managing people around daughter } \\
\text { Changing lifestyle } \\
\text { Learn to trick }\end{array}$ & \\
\hline
\end{tabular}

